\title{
VÍNCULOS FAMILIARES E SOCIAIS NAS RELAÇÕES DOS IDOSOS
}

\author{
Cíntia Kroth Araújo ${ }^{1}$ \\ Claudia Maria Corrêa Cardoso ${ }^{2}$ \\ Etiane Pereira Moreira ${ }^{3}$ \\ Evelin Wegner ${ }^{4}$ \\ Silvia Virginia Coutinho Areosa ${ }^{5}$
}

\section{RESUMO}

O estudo identificou e analisou a percepção dos idosos sobre suas relações de amizade no âmbito familiar, buscando a promoção do envelhecimento com qualidade de vida. A pesquisa do tipo descritiva utilizou uma metodologia qualitativa, com entrevistas estruturadas, gravadas e transcritas para posterior análise. A população estudada foi composta por homens e mulheres maiores de 60 anos que frequentam grupos e serviços ligados à Universidade de Santa Cruz do Sul (UNISC). Foram analisadas as narrativas de 250 idosos com base na técnica de análise de conteúdo. As questões versavam sobre a forma de conciliar a vida familiar e a relação com os amigos, tendo sido constatados aspectos positivos e negativos acerca das relações estabelecidas entre os idosos e seus familiares. Os resultados em sua maioria apontam que os idosos conciliam a vida familiar e a relação com os amigos de forma satisfatória.

Palavras-chave: Envelhecimento. Relações familiares. Relações de amizades.

\section{ABSTRAT}

The study identified and analyzed the perception of the elderly about their friendly relations in the family, to foster the development of aging and quality of life. The research used a descriptive-type qualitative methodology, with structured interviews that were taped and transcribed for later analysis. The study population was composed of men and women over 60 who attend groups and services related to University of Santa Cruz do Sul (UNISC). We analyzed the narratives of 250 elderly people based on the technique of content analysis. The questions were about how to reconcile family life and relationship with friends and was found positive and negative aspects of the relations established between the elderly and their families. The results show that mostly the elderly reconcile family life and relationship with friends satisfactorily.

Keywords: Aging. Family relationships. Friendships relationships.

\footnotetext{
Acadêmica de Psicologia pela UNISC. Bolsista (PUIC/UNISC). E-mail: cintia araujo1@yahoo.com.br

Acadêmica de Psicologia pela UNISC, Bolsista (PIBIC/CNPq).E-mail: claudia cardos02008@yahoo.com.br

Acadêmica de Psicologia pela UNISC. Bolsista (PIBIC/FAPERGS).E-mail: eti.ane@hotmail.com

Acadêmica de Farmácia pela UNISC. Bolsista (PIBIC/FAPERGS). E-mail: evelinwegner@hotmail.com

Doutora em Serviço Social. Docente do Departamento de Psicologia e do Programa de Pós-Graduação em Desenvolvimento Regional da UNISC. E-mail: sareosa@unisc.br
} 


\section{INTRODUÇÃO}

O Brasil tem o desafio de enfrentar as transformações que estão ocorrendo em seu perfil etário: o número de pessoas idosas está crescendo rapidamente com o aumento da expectativa de vida, conhecido como longevidade. Diante desse panorama social, o país vem desenvolvendo programas que atendam às demandas desses idosos e que ofereçam condições para um envelhecer com qualidade de vida. Os censos demográficos têm demonstrado o aumento da população idosa, que já chega a quase 20 milhões de brasileiros com mais de 60 anos (IBGE, 2008). Esse crescimento da população idosa se deu de maneira bastante acentuada na última década: a faixa de 65 anos e mais cresceu $49,2 \%$ e a faixa de mais de 90 anos cresceu $65 \%$.

A gerontologia, que tem como objetivo estudar e tratar dos aspectos que envolvem o envelhecimento, sejam eles biológicos, sociais, psíquicos, entre outros, busca promover pesquisas que possam estabelecer os fatores envolvidos na questão do envelhecimento (PAPALÉO NETTO, 2006). O envelhecimento com qualidade tem sido, pois, preocupação dos estudiosos da área que buscam soluções para a inserção social do idoso, dentre as quais merecem destaque as atividades de lazer, educação, esporte que propiciam a convivência entre grupos da mesma faixa etária (COSTA, 2010).

A velhice hoje é vista não como uma categoria natural, mas socialmente construída; portanto, "não permite um conceito absoluto, possibilitando que uma nova condição seja estabelecida. Logo, envelhecimento é um processo" e, dessa, forma não ocorre de um dia para o outro, mas se constrói ao longo da existência humana (BERNARDES, 2007, p.117). Assim, a forma como se dá a representação do envelhecimento na sociedade interfere diretamente sobre o ser que envelhece.

Existem, no entanto, duas formas de oferecer suporte social aos idosos: as redes formais e as redes informais. A rede de apoio social formal consiste em hospitais, ambulatórios médicos entre outras áreas da saúde, casas geriátricas, casa de repouso, asilos, centros-dia, além dos profissionais da área da saúde. As redes de apoio informal são representadas pelos familiares, amigos e vizinhos que oferecem apoio em diferentes âmbitos da vida do idoso. A família é a primeira rede de apoio para o idoso, onde este encontra a assistência necessária para suas dificuldades e necessidades (ASSIS e AMARAL, 2010).

O contexto familiar representa, pois, um elemento fundamental para o bem-estar dos idosos, que encontram nesse ambiente apoio e intimidade para as diferentes situações com que se deparam, relações que asseguram um espaço de pertencimento com os familiares. A família contemporânea vem sofrendo transformações em relação ao surgimento de novos papéis e a longevidade tem proporcionado a convivência intergeracional, encontrando-se até quatro gerações em uma mesma residência. Esse panorama demonstra que a família, apesar das mudanças frente a diversas situações, continua sendo um local de extrema importância para nutrir afetos e proteção aos idosos (ARAÚJO, 2010).

Assim, os vínculos que os idosos estabelecem no decorrer da vida são formados pelo grupo familiar, e por amizades na comunidade onde moram. Essas relações propiciam uma sensação de pertencimento e, esse fator, tem sido reconhecido como aspecto fundamental para um envelhecimento com qualidade de vida. Essas redes de apoio ajudam os idosos durante seu processo de envelhecimento, assegurando maior autonomia, independência, bem-estar e saúde (TRIADÓ e VILLAR, 2007). 
As redes de apoio social são também muito importantes e necessárias para a manutenção da saúde emocional ao longo de todo o ciclo de vida. Entretanto, em seu decorrer, vão sofrendo transformações na sua estrutura, de acordo com as necessidades de cada indivíduo. Algumas das mais importantes funções dessas redes de apoio social, para aqueles que estão na terceira idade, são: criar novos contatos sociais; fornecer e receber apoio emocional; obter garantia de que são respeitados e valorizados; manter sentimento de pertencimento a uma rede de relações comuns e fornecer suporte para aqueles idosos que sofreram perdas físicas e sociais (NERI, 2008).

Este estudo pretendeu conhecer as relações familiares e de amizade dos idosos de ambos os sexos, a partir dos 60 anos, que frequentam grupos de convivência para a Terceira Idade e serviços ligados à Universidade de Santa Cruz do Sul (UNISC). Buscou identificar a importância para o idoso dos vínculos de amizade dentro e fora da família e o papel que esses vínculos desempenham para a manutenção de sua saúde. Analisar os aspectos positivos e negativos que essas relações acarretam é fundamental para propor ações que contribuam para a promoção de saúde e para a qualidade de vida dos idosos.

\section{METODOLOGIA}

Esta pesquisa descritiva utilizou uma metodologia qualitativa, com entrevistas estruturadas. Teve sua aprovação no Comitê de Ética em Pesquisa com Seres Humanos da Universidade de Santa Cruz do Sul - UNISC (Parecer CAAE - no 0023.0.109.000-09). Foram feitas entrevistas individuais gravadas com 250 idosos no ambiente do seu grupo, tendo os mesmos assinado termo de consentimento livre e esclarecido. A análise das entrevistas foi feita através da técnica de análise de conteúdo (BARDIN, 2004). Este artigo aborda a questão "É fácil para você conciliar a vida familiar e a relação com seus amigos? Por quê?".

As entrevistas foram extensas e abordaram vários aspectos relacionados à vida, permitindo que o tema: "percepção dos idosos sobre suas relações" emergisse naturalmente durante diversos momentos e vários aspectos pudessem ser captados. Essas, aliás, é outra vantagem dos estudos qualitativos: os entrevistados têm oportunidades de "abrir" as questões fechadas, assim como de retomar ou rever posições assumidas em outro contexto ou sob motivação diferente. A amostra da pesquisa, após a finalização da coleta de dados e validação das entrevistas, ficou composta de 250 sujeitos idosos e os resultados encontrados serão apresentados a seguir.

A população deste estudo foi composta por indivíduos de ambos os sexos, maiores de 60 anos: $78 \%(n=196)$ são mulheres e $22 \%(n=54)$ são homens. Pode-se perceber uma diferença significativa em relação à participação dos homens e das mulheres nos grupos de convivência e nas atividades ligadas à terceira idade. Dos sujeitos entrevistados: $44 \%(n=110)$ são casados; e 4\% ( $n=10)$ têm uma união estável; 39\% ( $n=97)$ são viúvos; $13 \%$ ( $n=33)$ estão entre os solteiros, divorciados e separados, respectivamente. Em relação às idades dos idosos entrevistados, essas variam entre 60 e 88 anos, sendo que $31 \%(n=78)$ estão na faixa etária de $60-65$ anos; $28 \%(n=70)$ entre $66-70$ anos; $22 \%(n=56)$ entre $71-75$ anos; $16 \%$ $(n=39)$ entre $76-80$ anos; e apenas $3 \%(n=7)$ entre $81-88$, anos que seriam os idosos longevos da quarta idade. 


\section{DISCUSSÃO DE RESULTADOS}

A partir dos dados coletados em projetos desenvolvidos dentro da Universidade de Santa Cruz do Sul, como a hidroginástica, o dançar na terceira idade, a oficina do movimento, o grupo de hipertensos e diabéticos, e outros grupos fora da instituição em Santa Cruz do Sul e na região dos Vales do Rio Pardo e do Taquari, foi possível realizar a análise qualitativa dos 250 sujeitos entrevistados. Os resultados são aqui apresentados, destacando-se os aspectos positivos e negativos em relação à capacidade do idoso de conciliar as relações familiares com as relações de amizade, encontrados no conteúdo das falas dos idosos pesquisados.

\subsection{Aspectos positivos}

Entre os resultados encontrados nas entrevistas destacam-se, através do discurso dos entrevistados, categorias que abordam aspectos positivos, ligados a situações da vida diária dos idosos e que trazem benefícios de forma indireta para sua saúde. Essas categorias, descritas a seguir apontam a importância dos vínculos familiares e sociais que os idosos estabelecem e que acabam sendo fundamentais na qualidade de vida.

\section{a) Facilidade de se relacionar}

Os idosos entrevistados destacam a facilidade de se relacionar tanto com os familiares, quanto com os amigos. Compreende-se que essa questão está relacionada com a autoestima do idoso que se percebe de forma positiva. Eles relatam serem pessoas fáceis de conviver, pois respeitam e compreendem o próximo. Procuram sempre fazer as coisas da melhor forma e se dar bem com todas as pessoas, como se pode observar na seguinte fala: "É fácil porque na familia a gente já tem aquele relacionamento bom e com os amigos também temos relacionamento bom. A gente procura se dar bem, não maltratar ninguém, cada um tem uma opinião, tem que dar atenção para todo mundo" (Homem, 64 anos, Casado).

A relação com o outro é para o idoso muito importante, sendo o isolamento social algo extremamente temido. Com o envelhecimento, as relações familiares, pessoais e sociais aparecem sendo de grande importância como fonte de alimentação, regulação e organização. (VOLICH, 2009).

Tomando como pressuposto que a vida é intimamente fundamentada pelas relações sociais e que essas se realizam dentro de uma família, um clã, um grupo, uma tribo, uma comunidade, seja qual for a designação, é certo que a interação é um elemento básico para a sobrevivência. Em cada fase da vida, da infância à velhice, faz-se parte de um contexto que influencia as ações sociais dos outros sobre nós e de nós sobre os outros. Através das relações sociais aprende-se, troca-se afeto, informações, recebe-se e presta-se apoio, constrói-se e mantêm-se a identidade (GÜNTHER, 2009).

A rede familiar e de amigos é constituída por relações primárias que se caracterizam em sua natureza íntima e emocional, que são duradouras e propiciam aos idosos uma diversidade de papéis. As relações secundárias são formais e servem para atingir determinados objetivos, estando muitas vezes ligadas ao trabalho. Com o passar dos anos há uma diminuição dessas relações secundárias e os idosos encontram apoio em suas relações familiares e de amizade (HERNANDIS e MARTÍNEZ, 2005). 


\section{b) Apoio familiar}

Nessa categoria os idosos relatam como importante o apoio que recebem da família, para participar dos grupos, viajar, conviver com os amigos. A família incentiva os idosos a não ficarem sozinhos em casa, mas a procurar os amigos, visitá-los, ir às atividades de grupo. O fato de os amigos serem em comum ao casal ou à família, ou seja, terem amizades compartilhadas também facilita essa conciliação. É o que se pode observar na seguinte fala: "É muito fácil. Se eu quero viajar, ir pra praia com minhas amigas, meus filhos me ajudam, ligando todos os dias, vão me buscar, me esperam com jantar. Se eu quero viajar pra outro lugar sempre me ajudam, me oferecem dinheiro, incentivam que saia, a relação com meus amigos e minha familia é muito boa" (Mulher, 71 anos, Viúva).

Em qualquer fase da vida o sujeito necessita de algum apoio e para isso conta com a família e a comunidade, locais naturais de proteção e inserção social, dentro das redes informais. São esses lugares que possibilitam suporte para ampliar processos de inclusão social, vínculos relacionais e para criar projetos coletivos para o benefício da qualidade de vida. Portanto, o sujeito encontra na rede familiar, na convivência com os vizinhos, um suporte para o enfrentamento de dificuldades que encontra em seu cotidiano (LEMOS e MEDEIROS, 2006).

Sujeitos que não possuem um suporte social, seja ele com familiares e/ou amigos, tendem a ter mais dificuldade para lidar com o estresse, comparados àqueles que têm o suporte social. A ausência de parentes mais próximos, tais como cônjuge e filhos, está associada com doenças e mortalidade na terceira idade. O suporte familiar produz efeitos positivos na saúde. Esse suporte tende a reduzir os efeitos negativos do estresse na saúde mental, possibilitando assim, uma influência positiva no bem-estar psicológico do idoso (ASSIS e AMARAL, 2010).

A família desempenha, pois, um papel de cuidado ao longo de toda a vida do sujeito (apoio econômico, emocional). Esse cuidado que a família propicia oferece menos riscos de uma possível institucionalização. A família constitui-se, assim, em um recurso fundamental para o familiar idoso, pois presta atenção direta e auxílio para possíveis problemas graves de saúde que podem ocasionar a perda de autonomia dessa pessoa. Os idosos que mantêm contato com suas redes sociais informais, como os amigos e vizinhos, terão dessas pessoas considerável apoio e cuidado no caso de ausência da família (HERNANDIS e MARTíNEZ, 2005).

\section{c) Apoio dos amigos}

Os idosos entrevistados nesta pesquisa referem que é fácil conciliar a vida familiar e a vida com os amigos, devido à importância que os amigos têm nas suas vidas, tanto para se divertir, como para conversar, brincar, trocar ideias, se distrair, participar dos grupos de convivência. Relatam ser muito saudável para eles ter uma relação de amizade, pois muitas vezes são os amigos que servem de companhia quando os familiares trabalham ou não moram mais em casa. E isso pode ser observado nesta fala:"Porque eu gosto de conversar, eu gosto das amizades, eu gosto de festinha, gosto de estar junto, a gente faz os nossos encontros, se reúne pra conversar, pra tomar um chimarrão com bolo, com qualquer uma coisa assim, às vezes uma janta junto, nós fizemos isso assim, hoje nós vamos jantar junto e é isso, se reunimos" (Mulher, 66 anos, Viúva). 
Segundo Triadó e Villar (2007), as amizades constituem um importante apoio social e são fundamentais também pela faixa etária comum, indicando experiências de vida parecidas, recordações, opiniões e valores similares. Essas amizades são relações livres, voluntárias, baseadas na reciprocidade e no afeto, diferenciando, assim, das relações familiares que são essenciais ao sujeito.

Construir relações de amizade na velhice não é uma tarefa simples, devido à possível limitação do idoso ao convívio familiar e às perdas dos iguais. Quando transcendem a família, os relacionamentos se ampliam, enriquecendo e oportunizando formas diferentes de viver. "Compartilhar o momento presente, relembrar experiências passadas ou mesmo planejar encontros são algumas das possibilidades nos momentos em que os idosos estão juntos" (ARGIMON e VITOLA, 2009, p.29).

\section{d) Separar a família dos amigos}

Nessa categoria, os idosos referem que a maneira que encontraram para conciliar a vida familiar e a relação com os amigos é separando essas relações. Encontram facilidade por ter amigos pessoais, diferentes dos amigos dos filhos. Os entrevistados relatam que disponibilizam um tempo para os amigos e para a família dedicam outro espaço. $E$ isso pode ser observado na seguinte fala: "Eu não envolvo muito a família e os amigos. A família, eu vejo em casa; e os amigos, nos grupos que eu vou" (Mulher, 73 anos, Viúva).

$\mathrm{O}$ apoio que a família disponibiliza ao idoso tem o papel de proporcionar um bem-estar significativo. Aqueles idosos que são casados têm um fator a mais, que são as relações informais que mantém, pois com um companheiro há possibilidade de se vivenciar diversas experiências que são compartilhadas em conjunto, como a relação com os filhos e os netos, que acabam funcionando como uma proteção para a saúde, principalmente para os homens idosos (HERNANDIS e MARTÍNEZ, 2005).

Os grupos de convivência têm sido uma alternativa estimulada em todo o Brasil, pois são uma forma de interação, inclusão social e principalmente uma maneira de resgatar a autonomia, de viver com dignidade. As redes de relações, de amizades e vizinhança são importantes fontes de suporte social e estão relacionadas ao sentimento de bem-estar. Do mesmo modo, a satisfação dos idosos na convivência com outras pessoas, além dos familiares, pode aumentar de intensidade ao longo da vida, melhorando inclusive a qualidade de vida. Nesses grupos de convivência, que fizeram parte do estudo, os idosos encontram indivíduos que apresentam as mesmas necessidades de convívio social. Nesses espaços surge a oportunidade para estabelecer novas amizades, ampliar os conhecimentos e, principalmente, afastar a solidão (SPOSITO et al., 2010).

\section{e) Disponibilidade de tempo}

Os idosos referem que ter tempo "de sobra" facilita a conciliação, pois assim podem organizar melhor seu tempo e suas atividades diárias. Dessa forma, conseguem tempo para família, para visitar os amigos, conversar, tomar chimarrão, ou seja, para conciliarem as diversas atividades e relações do seu dia a dia. Com essa programação relatam conseguir tempo para as duas relações, pois necessitam da família e também dos amigos para uma vida saudável e feliz. Alguns referem que a aposentadoria influencia de forma positiva para obtenção desse tempo disponível, como se observa na fala de uma idosa: "Trabalho pouco e 
estou aposentada, assim consigo conciliar por causa do tempo disponível" (Mulher, 63 anos, Casada).

Neste estudo, o tempo disponível devido à aposentadoria é visto como algo positivo para os idosos. Estão conseguindo, assim, realizar novas descobertas e construir novos projetos de vida. Segundo Pacheco e Carlos (2006), com a chegada da aposentadoria o sujeito precisa buscar uma ampliação das suas redes sociais, através de clubes, associações, atividades religiosas, grupos de viagens, esportivos, culturais, de lazer, de voluntariado, entre outros, e não se restringir apenas às relações referentes ao trabalho/profissão que foram exercidas.

A aposentadoria, no entanto, pode ter um sentido diferente quanto ao gênero. Geralmente as mulheres buscam se manter ativas encontrando outras atividades para realizar. Isso permite que desenvolvam um sentimento de utilidade, enquanto provedoras do seu ambiente, tanto doméstico como social. No caso dos homens, que não possuem uma supremacia com relação ao espaço doméstico, algo criado socialmente para o sexo feminino, esses buscam novas atividades para vivenciar neste momento em que estão liberados do trabalho (PACHECO e CARLOS, 2006).

\section{f) Liberdade}

Nessa categoria, muitos idosos referem ter uma grande liberdade para se relacionar com os amigos, devido ao fato de, geralmente, estarem morando sozinhos. Como os filhos já construíram suas famílias e não estão mais em casa, sobra-lhes mais tempo para as relações de amizade. Outros relatam que, mesmo morando com os familiares, têm liberdade e autonomia para sair com os amigos, relações que não interferem na relação familiar. Isso se pode observar na seguinte fala: "É fácil conciliar: eu saio quando eu quero, volto quando quero, eu tenho liberdade" (Mulher, 62 anos, Casada).

A perda da liberdade é bastante temida pelo idoso, quando esse não tem mais condições de morar sozinho. Frente à doença ou à invalidez, necessita muito do apoio da família para manter a autonomia e a independência, mesmo que parcial. A solução das questões de dependência vai requerer aceitação das limitações do idoso e a capacidade de permitir-se ser dependente quando necessário. É indispensável também ao filho adulto a aceitação de seu papel filial, assumindo responsabilidade por aquilo que pode fazer pelos pais que estão envelhecendo, respeitando as limitações e a liberdade desses (VOLICH, 2009).

Ajudar o idoso a manter uma vida autônoma, dando condições de gerir suas necessidades básicas, sua vida diária e a capacidade de viver independentemente, pode influenciar na manutenção das suas capacidades cognitivas (ARGIMON e VITOLA, 2009). Na velhice a dependência física é, com muita frequência, confundida com dependência para a tomada de decisões, o que dá origem a um paternalismo social que, por sua vez, gera consequências, como fazer tudo em lugar do idoso e negar sua liberdade, autonomia e capacidade de escolha (BALTES e SILVERBERG apud MAZO et al., 2009).

Manter a autonomia e a independência são condições essenciais para a qualidade de vida do idoso, pois the permite realizar suas atividades cotidianas sem depender de outros, o que possibilita garantir sua capacidade de decisão. O grau de autonomia e independência de uma pessoa idosa é avaliado conforme desempenha suas tarefas no dia a dia, sempre considerando o contexto sociocultural em que vive. O contexto exerce influência nas oportunidades e possíveis restrições na autonomia e na independência do idoso (LEMOS e MEDEIROS, 2006). 


\subsection{Aspectos negativos}

Nem todas as categorias encontradas nas entrevistas referem-se a aspectos positivos, tendo sido também relatados aspectos negativos. Esses apontam as dificuldades que surgem em relação à falta de tempo e a não aceitação pela família de suas relações de amizade e de sua participação nas diversas atividades que são propostas pelos grupos de convivência para a terceira idade. Esses aspectos negativos em muitos casos inviabilizam os idosos de realizarem atividades de seu interesse e podem resultar em prejuízos para a sua saúde.

\section{a) Falta de tempo}

Alguns idosos encontram dificuldades de ver os amigos pela falta de tempo, pois estão comprometidos nas atividades da vida diária. Muitos ainda possuem dependentes (cônjuges, filhos ou netos), pessoas que dependem de seus cuidados na rotina da casa; outros ainda trabalham apesar da idade e não conseguem tempo para conciliar tudo. Isso podemos observar nas falas de duas idosas: "É, às vezes os amigos ficam de lado, pois são muitas atividades pra fazer" (Mulher, 63 anos, Casada). "Considero média, pois às vezes falta tempo" (Mulher, 76 anos, Casada).

A longevidade tem trazido um alargamento no tamanho das famílias, o que tem promovido a experiência de diferentes gerações conviverem entre si. Nessa nova configuração familiar, o idoso, muitas vezes, tem exercido a função de provedor da família, pois ajuda financeiramente os filhos e netos que, em muitas situações, continuam residindo na casa do idoso. Mesmo aposentados, ou seja, sem obrigações com o trabalho, os idosos muitas vezes são obrigados a realizar atividades diárias, sendo também responsáveis pelos cuidados e pela educação dos netos, o que acaba interferindo nesse tempo que poderia ser dedicado para suas atividades de lazer (TUR e OLIVARES, 2005).

A maior renda, através das aposentadorias e pensões, e o fato de o idoso normalmente possuir casa própria, tem proporcionado a ele maior capacidade de suporte familiar. Os benefícios previdenciários têm aumentado ao longo do tempo para ambos os sexos, o que faz com que muitos filhos e netos se tornem dependentes financeiramente dos idosos. É importante observar que os idosos ocupam significativamente a posição de chefia nesses arranjos. 0 tipo de arranjo mais comum, $44,5 \%$ no conjunto do país, é aquele no qual o idoso mora com seus filhos, em sua casa própria. O idoso de hoje contribui com quase $50 \%$ da manutenção da família, sendo o principal provedor. Os idosos muitas vezes abdicam de usar seu salário para necessidades pessoais, e inclusive de saúde, para garantir o sustento de seus familiares (AREOSA, 2010).

\section{b) Não aceitação da família}

Em relação à não aceitação pela família dos vínculos de amizade, alguns idosos dizem que a família não aceita bem a relação com os amigos, o que dificulta seus relacionamentos de amizade. Em muitos casos os idosos, especialmente mulheres, que possuem um companheiro ou são casadas, enfrentam dificuldade com o seu cônjuge, pois esse não sabe algumas vezes lidar com as amizades da sua companheira. Acaba, assim, colocando empecilhos nas relações de amizade de seu cônjuge o que resulta no impedimento de realizar atividades do seu interesse e de manter suas redes de amizade. Em outras situações 
são os filhos que acabam dificultando as relações, como se pode observar nas seguintes falas: "Os filhos não gostam quando eles estão em casa e vêm nossos amigos; os filhos acham que o espaço é deles e não gostam; então, tu não traz muitas pessoas em casa" (Mulher, 67 anos, Casada). "Não é fácil, porque os familiares não aceitam certas coisas" (Mulher, 79 anos, Casada).

Idosos que mantêm maior contato com amigos e familiares, provavelmente, vivam por mais tempo do que aqueles que se abstêm desses relacionamentos. É importante que a família proporcione ao idoso alternativas de interação social, ampliando os contatos sociais, visto que esses promovem sensação de conexão e bem-estar, auxiliando na adaptação à fase de envelhecimento. "Se, por um lado, os vínculos familiares são sentidos como importantes mantenedores de segurança emocional, por outro, relações fraternas, sem grau de parentesco, reforçam a interação social" (ARGIMON e VITOLA, 2009, p.29). As amizades possibilitam ao idoso apoio emocional, os amigos atuam como confidentes, conselheiros, auxiliam em momentos de necessidade, assim como em situações do dia a dia, proporcionando também companhia e aconchego. As amizades para os idosos são fontes significativas de satisfação e promovem sentimentos de bem-estar ao idoso (TRIADÓ e VILLAR, 2007).

\section{CONSIDERAÇÕES FINAIS}

Os resultados deste estudo em sua maioria apontam que os idosos conciliam a vida familiar e a relação com os amigos de forma satisfatória, indicando uma avaliação positiva. 0 idoso, segundo a pesquisa, está mais participativo, principalmente a mulher idosa, mantendo e ampliando sua rede de relações na Terceira Idade. É importante que esses sujeitos não percam suas amizades, seus encontros familiares, suas atividades de lazer, sua participação em grupos. Este estudo demonstrou que isso faz com que o envelhecimento possa ser visto de maneira positiva e até como algo desejado, pois os idosos continuam fazendo parte da sociedade, sentindo-se integrados e satisfeitos. Para o idoso, a autonomia e a manutenção da independência são mais importantes do que seu estado de saúde e as perdas que teve no processo de envelhecer, pois essas fazem com que possa manter seus vínculos sociais e, com isso, sua qualidade de vida.

\section{REFERÊNCIAS}

ARAÚJO, Eliana Novaes Procópio. Intervenções Psicogerontológicas na Promoção de Envelhecimento Bem-Sucedido. In: MALAGUTTI, W; BERGO, A. M. A. (Org.). Abordagem Interdisciplinar do Idoso. Editora: Rubio, Rio de Janeiro, 2010, p. 67-76.

AREOSA, S.V.C.; BULLA, L.C. Contexto social e relações familiares: o idoso provedor. In: AREOSA, Silvia (Org.). Terceira idade na UNISC: novos desafios de uma população que envelhece. Santa Cruz do Sul: EDUNISC, 2010, p. 108-129.

ARGIMON, I. I. de L; VITOLA, J. C. E a família, como vai? In: BULLA, L. C; ARGIMON, I. I. de L. (Org.). Convivendo com o familiar idoso. Porto Alegre: EDIPUCRS, 2009, p. 25-31. 
ASSIS, L. P. P; AMARAL, M. L. N. do. Envelhecimento e suporte social. In: COSTA, Geni de Araújo (Org.). Atividade física, envelhecimento e a manutenção da saúde. Uberlândia: EDUFU, 2010, p. 207-217.

BARDIN, Laurence. Análise de conteúdo. 3. ed. Lisboa: Edições 70, 2004. 281p.

BERNARDES, Maria Aparecida Fraga. Conselhos de representação: espaços para os idosos se organizarem na defesa de seus direitos. Revista Kairós, São Paulo: EDUC, v.10, n. 2, p. 107121, 2007.

COSTA, Geni de Araújo. Longevidade: um desafio para a sociedade. In: COSTA, Geni de Araújo (Org.). Atividade Física, Envelhecimento e a Manutenção da Saúde. Uberlândia: EDUFU, 2010, p. 23-41.

GÜNTHER, Isolda de Araújo. Envelhecimento, Relações Sociais e Ambiente. In: FALCÃO, D. V. da S; ARAÚJO, L. F. de. Psicologia do Envelhecimento. Editora: Alínea, Campinas, São Paulo, 2009, p. 11-25.

HERNANDIS, Sacramento Pinazo. El apoyo social y las relaciones sociales de las personas mayores. In: HERNANDIS, S.; P.; MARTINEZ, M.; S.; (Orgs.) Gerontología: Actualización, innovación y propuestas. Madrid: Pearson Educación S.A, 2005, p. 221-256.

IBGE - Instituto Brasileiro de Geografia e Estatística. Estimativas da População 2008. Disponível em: <http://www.ibge.gov.br/home/presidencia/noticias/noticia.visualiza. php?id.no ticia =1233\&idpagina=1 > Acesso em: 8 de out. 2008.

LEMOS, N; MEDEIROS, S. L. Suporte Social ao Idoso Dependente. In: FREITAS, Elizabete Viana de et. al. Tratado de Geriatria e Gerontologia. 2. Ed. Editora: Guanabara Koogan, Rio de Janeiro, 2006, p. 1227-1233.

LOPES, Andrea. Dependência, Contratos Sociais e Qualidade de Vida na Velhice. In: SIMSON, O. R. M. V et al. As Múltiplas Faces da Velhice no Brasil. 2. ed. Editora: Alínea, Campinas, São Paulo, 2006, p. 129-140.

MAZO et al. Atividade Física e o Idoso: Concepção Gerontológica. Editora Sulina. 3. ed. Revisada e ampliada. Porto Alegre, 2009.

NERI, Anita L. Palavras-Chave em Gerontologia. Campinas, SP: Editora Alínea, 2008.

PACHECO, J. L; CARLOS, S. A. Relações do Homem com o Trabalho e Processo de Aposentadoria. In: FREITAS, Elizabete Viana de et al. Tratado de Geriatria e Gerontologia. 2. ed. Editora: Guanabara Koogan, Rio de Janeiro, 2006, p. 1388-1393.

PAPALÉO NETTO, Matheus. O Estudo da velhice: Histórico, Definição de Campo e Termos Básicos. In: FREITAS, Elizabete V. et al. Tratado de Geriatria e Gerontologia. 2. ed. Rio de Janeiro: Guanabara Koogan, 2006, p. 2-12. 
SPOSITO, Giovana et al. Relações entre o bem-estar subjetivo e a funcionalidade em idosos em seguimento ambulatorial. Revista Brasileira de Fisioterapia, São Carlos, v. 14, n. 1, p. 819, jan./fev. 2010.

TRIADÓ, C; VILLAR, F. (Org.). Psicología de la vejez. Madrid: Alianza Editorial, 2007.

TUR, C. T.; OLIVARES, M. J. O. Las Relaciones Abuelos-Netos. In: HERNANDIS, S. P.; MARTínEZ, M. S. Gerontología: Actualización, Innoción y Propuestas. Editora: Pearson Educación. Madri- Espanha, 2005. p. 259 -287.

VOLICH, Rubens M. O corpo, entre a organização e o caos. In: CÔRTE, B.; GOLDFARB, D. C.; LOPES, R. G. da C. L. Psicogerontologia: fundamentos e práticas. Curitiba: Juruá, 2009. p. 4959. 